\title{
Anamnestic risk factor questionnaire as reliable diagnostic instrument for osteoporosis (reduced bone morphogenic density)
}

\author{
Leila Kolios ${ }^{1 *}$, Caner Takur ${ }^{2}$, Arash Moghaddam², Mirjam Hitzler ${ }^{2}$, Heinrich Schmidt-Gayk ${ }^{3}$, Arnold J Suda ${ }^{2}$, \\ Bernd Höner ${ }^{4}$, Paul A Grützner ${ }^{2}$ and Christoph Wölff ${ }^{2}$
}

\begin{abstract}
Background: Osteoporosis is a major health problem worldwide, and is included in the WHO list of the top 10 major diseases. However, it is often undiagnosed until the first fracture occurs, due to inadequate patient education and lack of insurance coverage for screening tests. Anamnestic risk factors like positive family anamnesis or early menopause are assumed to correlate with reduced BMD.

Methods: In our study of 78 patients with metaphyseal long bone fractures, we searched for a correlation between anamnestic risk factors, bone specific laboratory values, and the bone morphogenic density (BMD). Each indicator was examined as a possible diagnostic instrument for osteoporosis. The secondary aim of this study was to demonstrate the high prevalence of osteoporosis in patients with metaphyseal fractures.

Results: $76.9 \%$ of our fracture patients had decreased bone density and $43.6 \%$ showed manifest osteoporosis in DXA (densitometry) measurements. Our questionnaire, identifying anamnestic risk factors, correlated highly significantly $(p=0.01)$ with reduced BMD, whereas seven bone-specific laboratory values $(p=0.046)$ correlated significantly.

Conclusions: Anamnestic risk factors correlate with pathological BMD. The medical questionnaire used in this study would therefore function as a cost-effective primary diagnostic instrument for identification of osteoporosis patients.
\end{abstract}

\section{Background}

The WHO included osteoporosis in the list of the ten major worldwide diseases [1]. Approximately 200 million patients worldwide, 44 million in the US and about 7.6 million in Germany, suffer from osteoporosis [2-4]. The high prevalence of osteoporosis in current populations becomes more stressing to health care systems as osteoporosis rates increase with age, and as populations adopt unhealthy lifestyles with reduced physical activity and unbalanced diets [5]. In the western industrial nations there is an immense imbalance between inadequately treated osteoporosis and the continually increasing life expectancies [6]. In Germany, costs incurred due to osteoporosis result from osteoporosis associated

\footnotetext{
* Correspondence: leilakolios@freenet.de

'Department for Plastic-, Reconstructive and Handsurgery, Burn Care Centre, BG Unfallklinik Ludwigshafen, Ludwig-Guttmann-Str.13, 67071 Ludwigshafen, Germany

Full list of author information is available at the end of the article
}

fractures, especially fractures of proximal femur, and include acute care, rehabilitation, and extended nursing care. All in all, the expenditure amounts to 5 billion euros annually $[6,7]$. A proximal femur fracture is often the first indication of manifest osteoporosis. Preventional diagnostics such as DXA-measuring or laboratory examination, amounting to approximately 15 million euros per year, are not currently covered by health insurance.

There are various risk factors, which are assumed to highly correlate with osteoporosis. These are anamnestic details of the patient's medical history as for example: positive family anamnesis, early menopause, nicotine abuse, age $>70$ years. They are included as osteoporosisspecific risk factors in the recommendations of the German Society of Osteology (DVO, Dachverband Osteologie e.V.). The aim of this study is to demonstrate the high prevalence of osteoporosis in patients with metaphyseal fractures, and, secondly, to show the competence of
C Biomed Central

() 2011 Kolios et al; licensee BioMed Central Ltd. This is an Open Access article distributed under the terms of the Creative Commons Attribution License (http://creativecommons.org/licenses/by/2.0), which permits unrestricted use, distribution, and reproduction in any medium, provided the original work is properly cited. 
anamnestic risk factors and bone specific laboratory values in osteoporosis identification.

\section{Methods}

Between January 2008 and May 2010, 78 patients aged 40 to 80 years who presented to our hospital with a metaphyseal fracture of the distal radius, proximal humerus and proximal femur with an obligatory indication for surgical stabilization were included in this study. Exclusion criteria were: polytrauma, significant soft tissue injury, extensive open fractures, $>24 \mathrm{~h}$ mechanical ventilation after surgery, dialysis, collagenosis, chronic inflammatory bowel disease, haematological disorders and malignancies, and long-term therapy with immunosuppressants.

$\mathrm{X}$-rays of the fracture region and the lumbar spine in anterior-posterior and lateral views were performed of all patients. Lumbar spine radiographs were used to exclude morphological changes of the vertebrae leading to inaccurate values in DXA bone density measurement. BMD was examined at the lumbar spine, total hip and hip subregions using dual energy X-ray absorptiometry DXA (Lunar iDPX, GE Medical Systems Germany, Solingen, Germany) based on Encore TM Version II.X software.

Using normative data for young Caucasian adults, BMD was categorized as normal, low, or osteoporotic, as defined by the World Health Organization [8]. Participants with a $\mathrm{T}$-score $\leq-2.5 \mathrm{SD}$ were categorized as having osteoporosis.

To collect the anamnestic risk factors of patients, we established a standardized questionnaire according to the recommendations of the German Society of Osteology (DVO, Dachverband Osteologie e.V.). The questionnaire included clinical risk factors (19 for men, 21 for women) as shown in table 1 [9]. The questionnaire was filled out with one member of the study group present, to provide assistance if needed.

Laboratory analysis was performed the morning after injury in a fasting state. Eleven bone specific parameters reflecting bone metabolism were examined: intact $\mathrm{PTH}$ [10], 25-hydroxy vitamin D3 (25-OH-D3) [11], betacrosslaps ( $\mathrm{B}$-CTX), pyridinoline in urine, desoxypyridinoline in urine (DPD) $[10,12]$, procollagen type $1 \mathrm{~N}$ propeptide (PINP) [10], creatinine in urine [13], estradiol [10], homocysteine, vitamin B12 and folate [14,15]. Every pathologic aberration from the standard value was assessed with one point.

Statistics were performed using SPSS 11.0.0 (IBM Germany, Munich, Germany) and Microsoft Excel 2003/ 2007 software, Microsoft Corp. Washington, USA. Using Spearman's rank correlation coefficient, the single anamnestic risk factors and laboratory parameters were correlated with the reduced BMD values. $\mathrm{P} \leq 0.05$ was considered to be significant and $\mathrm{p} \leq 0.01$ highly significant. In addition we performed a multivariable analysis in order to adjust for potential confounders. With the method of
Table 1 Medical questionnaire of anamnestic risk factors for reduced BMD

\begin{tabular}{|c|c|c|c|}
\hline & men & women & total \\
\hline Reduction of body height $>4 \mathrm{~cm}$ & 3 & 9 & 12 \\
\hline Alcohole abuse & 2 & 4 & 6 \\
\hline Age $>70$ & 2 & 14 & 16 \\
\hline Anorexia nervosa & 0 & 0 & 0 \\
\hline Anticonvulsive therapy & 1 & 0 & 1 \\
\hline Already suffered osteoporotic fractures & 2 & 9 & 11 \\
\hline $\mathrm{BMI}<20 \mathrm{~kg} / \mathrm{m}^{2}$ & 0 & 0 & 0 \\
\hline Chronical renal or hepatic disease & 0 & 2 & 2 \\
\hline Family history & 3 & 19 & 22 \\
\hline Early menopause (< $45 . \mathrm{Lj}$.) & - & 13 & 13 \\
\hline Late menarche (> 15. Lj.) & - & 2 & 2 \\
\hline Highdose heparintherapy & 0 & 1 & 1 \\
\hline Hormon replacement therapy & 0 & 6 & 6 \\
\hline Hyperparathyroidism & 0 & 0 & 0 \\
\hline Hyperthyroidism & 0 & 4 & 4 \\
\hline (N)IDDM & 1 & 3 & 4 \\
\hline Immobilisation, Inactivity & 1 & 1 & 2 \\
\hline Malabsorption-syndrome & 0 & 0 & 0 \\
\hline Multiple Sclerosis & 0 & 1 & 1 \\
\hline Nikotine abuse & 3 & 12 & 15 \\
\hline Rheumatoid Arthritis & 0 & 4 & 4 \\
\hline
\end{tabular}

The right columns show the frequence of aberrations of the single risk factors in our study.

"ordinal logistic regression" we examined age, sex and BMI as possible confounders with the variables BMD, risk factors and laboratory values.

The study is approved by the local Ethical Committee of Heidelberg with the approval number 1572002. All patients gave their informed consent prior to their inclusion in the study.

\section{Results}

A total of 78 patients who suffered a metaphyseal fracture of the distal radius, proximal humerus or proximal femur between January 2008 and May 2010 were included in this study. The average patient age was 62.2 years with a range from 41.9 to 77.6 years. The 12 male patients had an average age of 65.4 years, the 66 female patients of 61.6 years. 41 patients had a distal radius fracture, 23 patients a proximal humerus fracture and 14 patients suffered a proximal femur fracture.

In DXA-measuring $76.9 \%$ of patients showed a pathologic bone density. 34 (43.6\%) patients had a decrease in bone density in terms of osteoporosis, 26 (33.3) patients had osteopenic BMD. 18 (23.1\%) of patients had physiological findings (Figure 1). Among the male patients, 58.3\% showed manifest osteoporosis and $16.7 \%$ osteopenia. 


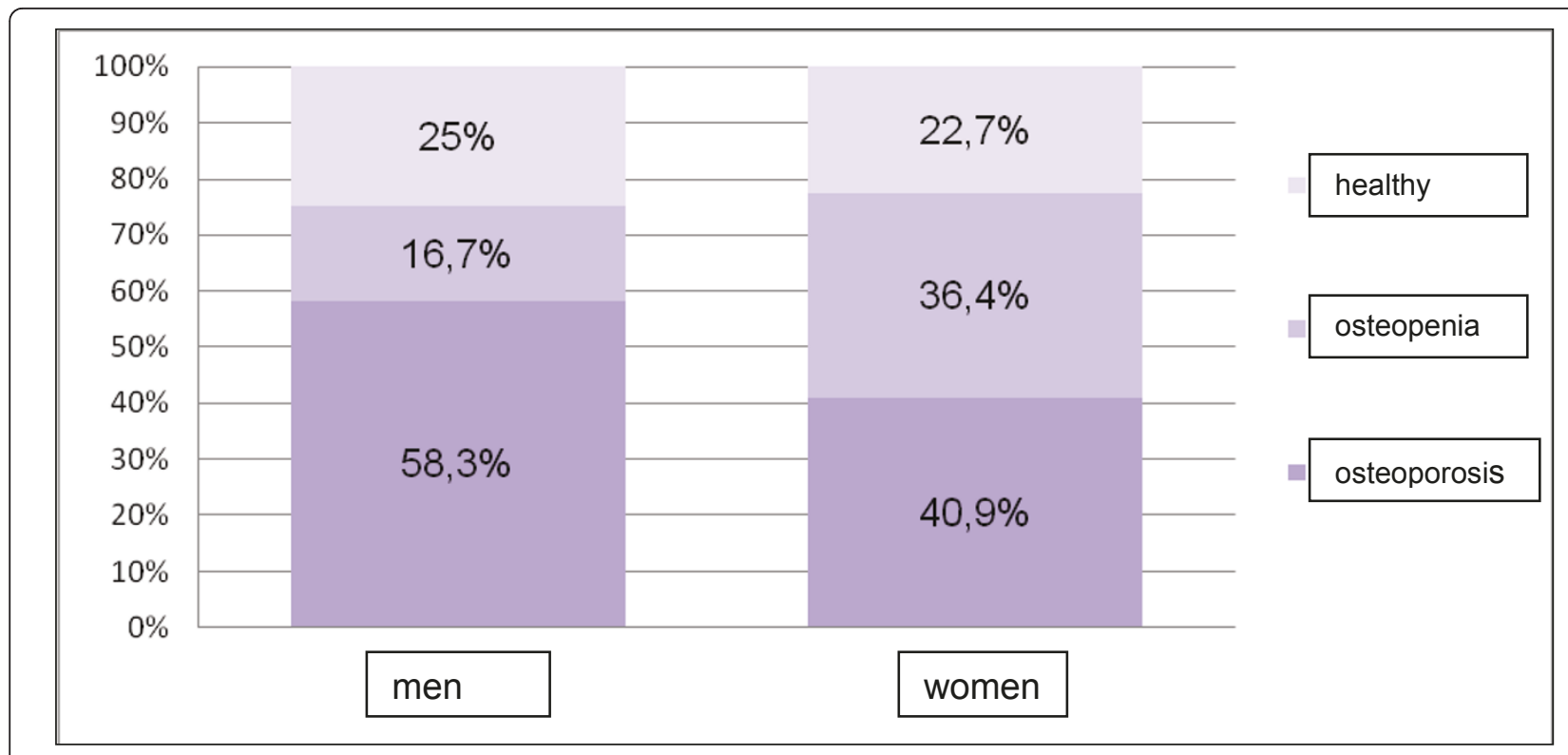

Figure 1 Results of DXA-measuring. Percentaged amount of healthy, osteopenic and osteoporotic values in women and men.

Female patients showed in $40.9 \%$ manifest osteoporosis and in $36.4 \%$ an osteopenia.

The frequency of the single anamnestic risk factors can be seen in table 1. The leading risk factors are: positive family history, age $>70$ years, nicotine abuse, early menopause, reduction of body height $>4 \mathrm{~cm}$ and previous osteoporotic fractures. There was no incident of 4 risk factors (anorexia nervosa, BMI $<20 \mathrm{~kg} / \mathrm{m}^{2}$, hyperparathyreoidism, malabsorption syndrome) in our collective.

Questionnaire risk factors correlated with reduced bone density values. Spearman's rank correlation allowed separate consideration of the individual risk factors reduced bone density. The 10 anamnestic risk factors: reduce of body height $>4 \mathrm{~cm}$, alcohol abuse, age $>70$ years, anticonvulsant therapy, previous osteoporotic fractures, early menopause (<45years), hyperthyroidism, immobilization, multiple sclerosis and nicotine abuse showed a highly significant correlation $(\mathrm{p}=0.01)$ with low bone density (Figure 2).

Table 2 shows the frequency of pathological laboratory values in our collective. Laboratory values of 67 patients were evaluated; 11 patients declined blood sample collection. The main pathologic laboratory values are: homocysteine (51 patients), 25-OH-D3 (42 patients), and desoxypyridinoline (31 Patients). The fewest aberrations were seen in B-CTX (13 patients), estradiol (7 patients) and vitamin B12 (6 Patients) measurings.

For statistical analyses, Spearman's rank was used to correlate abnormal laboratory values with a decrease in bone density. The highest correlation $(\mathrm{p}=0.046)$ was noted in parathyroid hormone, 25-OH-D3, procollagen type $1 \mathrm{~N}$ propeptide, desoxypyridinoline, creatinine, homocysteine and vitamin B12 (Figure 3).

The multivariable analysis showed no significant effects with the variables; thus the age, sex and BMI of patient do not have a confounding effect.

\section{Discussion}

In this study, nearly $80 \%$ of patients who suffered a metaphyseal fracture showed pathologically reduced bone mineral density, and nearly $50 \%$ of the patients were diagnosed with manifest osteoporosis. $84.6 \%$ of our

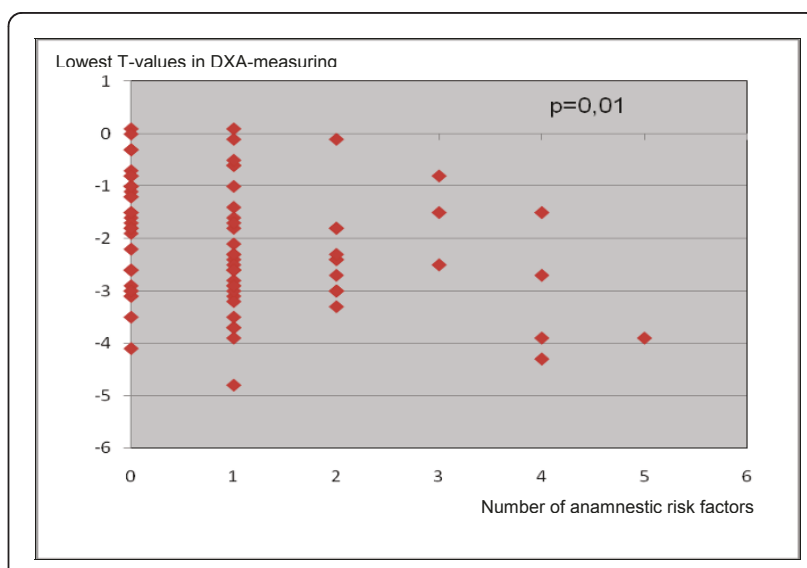

Figure 2 Diagram presenting the correlation between the lowest T-values of DXA-measuring with increasing number of anamnestic risk factors. The correlation of the most important risk factors and a reduced BMD is highly significant $(p=0.01$, Spearman's rank correlation). 
Table 2 Frequence of aberrations of bone specific laboratory parameters in women, men and in total

\begin{tabular}{lccc}
\hline & men & women & total \\
\hline Parathormone intakt & 5 & 22 & 27 \\
\hline B-CTX & 7 & 35 & 42 \\
\hline Pyridinoline (urine) 33 & 2 & 11 & 13 \\
\hline Procollagen Typ I N propeptide & 1 & 25 & 29 \\
\hline Desoxypyridinoline (urine) & 4 & 14 & 15 \\
\hline Creatinine (urine) & 4 & 27 & 31 \\
\hline Estradiol & 6 & 12 & 18 \\
\hline Homocysteine & 1 & 6 & 7 \\
\hline Vitamin B12 & 7 & 44 & 51 \\
\hline Folate & 2 & 4 & 6 \\
\hline
\end{tabular}

patients were postmenopausal women. Our results coincide with current research; Vogel et al. [16] found osteoporosis in $72 \%$ of acute limb fracture patients (only $4 \%$ showed normal bone density). Another Dutch study [17] evaluated fractures resulting from low energy trauma and found manifest osteoporosis in $67 \%$ of patients. (Hegemann et al defined the T-Score as $<-2.0$ for osteoporosis, compared to $<-2.5$ in our study).

Having identified one of the major problems in treatment of osteoporosis: post fracture diagnosis; we have identified the major cause of the progression of this disease: the therapeutic window in which to minimize fracture risk is overlooked. Due to the exceptionally high morbidity and mortality after osteoporotic fractures, prevention is essential. However, as mentioned, the costs for preventional screenings such as DXA-measurement or laboratory examination (amounting to approximately 15 million euros per year) are not currently covered by

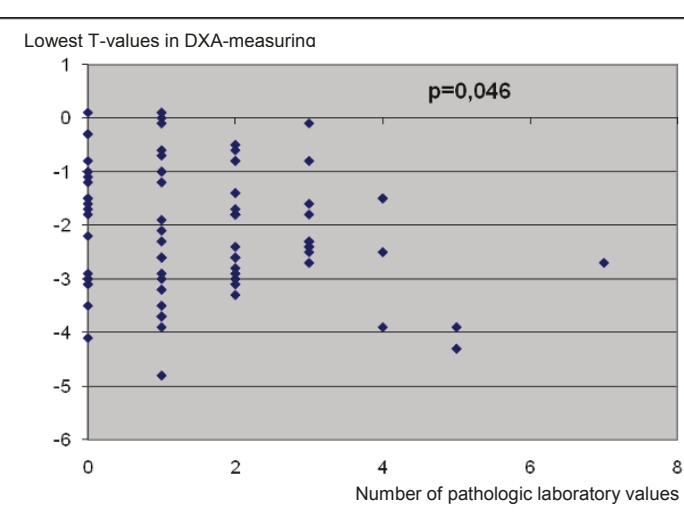

Figure 3 Diagram presenting the correlation between the lowest T-values of DXA-measuring with increasing number of pathologic laboratory parameters. The correlation of the seven bone specific values and a reduced BMD is significant ( $p=0.046$, Spearman's rank correlation).
German health insurance companies [6]. Furthermore, bone loss progresses silently, and without patient education and preventional screenings, few patients would recognize the risk $[18,19]$.

A safe, simple and cost effective instrument for osteoporosis diagnosis is essential. The results of this study show that a simple medical questionnaire containing 10 anamnestic questions is a reliable test to quickly and efficiently screen large numbers of patients for reduced BMD. With early detection of bone loss and consecutive implementation of antiosteoporotic therapy, the risk of osteoporotic fractures with the coinciding high morbidity and mortality can be reduced, thereby achieving a massive decrease in health care costs.

The most important risk factors identified by the questionnaire are as follows:

Patient age represents a core variable for osteoporosis risk [20] increasing age increases fracture risk $[8,21]$. Age related decreases in estrogen lead to disrupted microarchitecture of trabecular bone [22]. Thus, age is one of the most important risk factors for osteoporosis and therefore was included in the DVO.

The loss of $\geq 4 \mathrm{~cm}$ body height is risk factor for reduced $\mathrm{BMD}$, and may result from vertebral sintering due to osteoporotic change of trabecular structure. Joakimsen et al. [23] showed that patients with a maximal height of $168 \mathrm{~cm}$ suffered fracture of the lower extremity 2.5 times more often.

Excessive alcohol consumption showed high significance with reduced BMD in our study. Kanis et al. [24] also demonstrated a correlation between high amounts of alcohol consumption and reduced BMD. The cause may be increased renal secretion of calcium. On the other hand, low alcohol consumption (one glass of wine per day) can positively influence bone mineral density [25].

Similar osteoporotic findings exist for nicotine abusers, due to a reduced enteral resorption of calcium [26]. Comparing smokers and non-smokers Kanis et al. [24] showed a significantly increased fracture rate in smokers. In addition, Law et al. [27] found out that the risk of bone loss caused by smoking is especially high in postmenopausal women over the age of 60 .

In the past, the high fracture rate under epileptic patients was explained by the convulsive seizures; however, the anticonvulsive pharmaceuticals are now known to reduce the enteral resorption of calcium, and thereby causing the high prevalence of reduced bone density found in this population [28-30].

Early menopause, before age 45 , is also defined as a risk factor for decreasing bone mass. The comparatively short estrogen exposition time is thought to enhance bone resorption [31]. Other authors propose nutrition as the cause [32]. 
Recent studies show that subclinical hyperthyroidism leads to a decreased bone mineral density [33,34]. Postmenopausal women with hyperthyroidism are especially vulnerable to bone mass loss [35]. The mechanism of action has been proposed by Katani et al. [36] and [37] Garnero et al. to be trijodthyronine (T3) induction of differentiation of osteoclasts. This leads to the creation of bone resorption products (e.g. pyridinoline, peptides of collagen) and excretion of calcium in the urine. T3 also stimulates osteoblasts, but all in all the balance is negative.

Another highly significant factor in our study was the immobilisation or inactivity of patients. Also DargentMoline [38] showed that a reduced mobility, activity and reduced musculature increases the risk of developing osteoporosis. Due to the missing mechanical exposure of the muscular-skeletal system, the bone tissue weakens [39]. This explains why patients with multiple sclerosis suffer a significantly reduced bone mineral density [40].

Our questionnaire represents a screening method; if reduced BMD is suggested, a complete diagnosis with clinical examination, laboratory tests, radiography and DXA measurement remain the gold standard to achieve a precise diagnosis of the extent, cause, and indicated treatment of pathological bone density.

As for the bone specific laboratory values, out of the 11 factors examined in this study, 7 showed a significant correlation to a reduced BMD, and are discussed below.

Most of our patients showed a lack of 25-OH vitamin D3, probably due to the reduced exposure to sunlight during winter. The lack of D3 leads to PTH increase which induces calcium decomposition in bone; possibly the cause of the high PTH levels found in our patients. Another cause of elevated PTH is primary or secondary hyperthyroidism [41-43]. Both low D3 and high PTH are important parameters in the diagnosis and treatment of osteoporosis in the DVO guidelines [9].

One of the most significant markers for osteoblast activity is the PINP (procollagen type $1 \mathrm{~N}$ propeptide), which is separated during synthesis of collagen. Increased values indicate active bone formation, and is typical for malignant tumors or osteoporosis $[12,44,45]$.

Desoxypyridinoline is a decomposition product of collagene and represents a specific marker for osteoclast activity. Various studies proved its reliability [46-48].

Creatinine levels detect secondary osteoporosis due to renal osteopathy. Homocysteine is mainly used for the identification of an atherosclerotic risk profile. Increased blood levels of homocysteine in conjunction with decreased vitamin B12, leads to a reduced BMD and, as reported by Leboff et al. [49] results in osteoporotic fractures. Further studies presented same findings [50,51]. Stimulation of osteoclast activity is presumed to be the mechanism by which a high level of homocysteine and a low level of vitamin B12 reduces of BMD [52].

\section{Conclusions}

In conclusion, there is a high prevalence of undiagnosed osteopenia and osteoporosis in patients suffering metaphyseal fractures. Both methods (medical questionnaire and laboratory analysis) examined in our study present reliable instruments for diagnostics of osteoporosis. Astonishingly, the cost-effective and "simple" medical questionnaire showed a high correlation with reduced BMD and therewith presents next to the laboratory values a powerful instrument for osteoporosis diagnostics.

\section{Integrity of research and reporting}

The study is approved by the local Ethical Committee of Heidelberg with the approval number 1572002. All patients gave their informed consent prior to their inclusion in the study.

\section{Author details}

'Department for Plastic-, Reconstructive and Handsurgery, Burn Care Centre, BG Unfallklinik Ludwigshafen, Ludwig-Guttmann-Str.13, 67071 Ludwigshafen, Germany. ${ }^{2}$ Department of Trauma and Orthopaedic Surgery, BG Trauma Center Ludwigshafen, Ludwig-Guttmann-Str.13, 67071 Ludwigshafen, Germany. ${ }^{3}$ Clinical Laboratory Limbach, Im Breitspiel 15, 69126 Heidelberg, Germany. ${ }^{4}$ Department of Social and Legal Sciences, SRH Hochschule Heidelberg, Ludwig-Guttmann-Str.6, 69123 Heidelberg, Germany.

\section{Authors' contributions}

LK participated in the evaluation of patients, data, statistics and wrote the paper, she has seen and approved the final version. CT participated in planning of the study, evaluation of patients and data and has seen and approved the final version. AM participated in planning of the study, evaluation of patients, data and statistics and has seen and approved the final version. $\mathrm{MH}$ participated in planning of the study, evaluation of patients and data and has seen and approved the final version. AS participated in planning of the study, evaluation of patients, data and statistics and has seen and approved the final version. HS-G participated essentially in establishment of laboratory analyses, their evaluation and statistics, but unfortunately died before submission of this study. $\mathrm{BH}$ participated substancially in planning of the study and performing of statistics and has seen and approved the final version. PAG participated in planning of the study, supervision of the study, evaluation of patients, data and statistics and has seen and approved the final version. CW participated substancially in planning of the study, supervision of the study, evaluation of patients, data and statistics and has seen and approved the final version.

\section{Competing interests}

The authors declare that they have no competing interests.

Received: 6 March 2011 Accepted: 17 August 2011

Published: 17 August 2011

\section{References}

1. Macdonald HM, New SA, Campbell MK, Reid DM: Influence of weight and weight change on bone loss in perimenopausal and early postmenopausal Scottish women. Osteoporos Int 2005, 16:163-171.

2. Cooper C: Epidemiology of osteoporosis. Osteoporos Int 1999, 9-2:2-8.

3. Reginster JY, Burlet N: Osteoporosis: a still increasing prevalence. Bone 2006, 38:4-9.

4. Haussler B, Gothe H, Gol D, Glaeske G, Pientka L, Felsenberg D: Epidemiology, treatment and costs of osteoporosis in Germany-the BoneEVA Study. Osteoporos Int 2007, 18:77-84

5. Macdonald HM, New SA, Golden MH, Campbell MK, Reid DM: Nutritional associations with bone loss during the menopausal transition: evidence of a beneficial effect of calcium, alcohol, and fruit and vegetable 
nutrients and of a detrimental effect of fatty acids. Am J Clin Nutr 2004, 79:155-165.

6. Minne HW, Pfeifer M, Begerow B, Pollahne W: Osteoporosis. Orthopade 2002, 31:681-979.

7. Gotte S, Dittmar K: Epidemiology and costs of osteoporosis. Orthopade 2001, 30:402-404.

8. Kanis JA, Johnell O, Oden A, Dawson A, De Laet C, Jonsson B: Ten year probabilities of osteoporotic fractures according to BMD and diagnostic thresholds. Osteoporos Int 2001, 12:989-995.

9. Pfeilschifter J: Osteoporosis-current diagnostics and therapy. Med Klin (Munich) 2009, 104:632-643.

10. Guder WG, Nolte J: Das Laborbuch für Klinik und Praxis. First ed Munich 2005, Elsevier.

11. Ledger GA, Burritt MF, Kao PC, O'Fallon WM, Riggs BL, Khosla S: Role of parathyroid hormone in mediating nocturnal and age-related increases in bone resorption. J Clin Endocrinol Metab 1995, 80:3304-3310.

12. Christenson RH: Biochemical markers of bone metabolism: an overview. Clin Biochem 1997, 30:573-593.

13. Kansal $S$, Fried $L$ : Bone disease in elderly individuals with CKD. Adv Chronic Kidney Dis 2010, 17:41-51.

14. Tucker KL, Hannan MT, Qiao N, Jacques PF, Selhub J, Cupples LA, Kiel DP: Low plasma vitamin B12 is associated with lower BMD: the Framingham Osteoporosis Study. J Bone Miner Res 2005, 20:152-158.

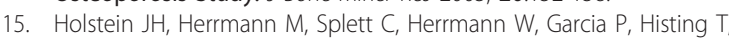
Graeber S, Ong MF, Kurz K, Siebel T, Menger MD, Pohlemann T: Low serum folate and vitamin B-6 are associated with an altered cancellous bone structure in humans. Am J Clin Nutr 2009, 90:1440-1445.

16. Vogel T, Dobler T, Bitterling H, Biberthaler P, Kanz KG, Pfeifer K, Bartl R, Mutschler W: Osteoporosis in traumatology. Prevalence and management. Unfallchirurg 2005, 108:356-364.

17. Hegeman JH, Willemsen G, Van Nieuwpoort J, Kreeftenberg HG, Van Der Veer E, Slaets JP, Ten Duis HJ: Effective tracing of osteoporosis at a fracture and osteoporosis clinic in Groningen; an analysis of the first 100 patients. Ned Tijdschr Geneeskd 2004, 148:2180-2185.

18. Brask-Lindemann D, Cadarette SM, Eskildsen P, Abrahamsen B Osteoporosis pharmacotherapy following bone densitometry: importance of patient beliefs and understanding of DXA results. Osteoporos Int 2010.

19. Berry SD, Misra D, Hannan M, Kiel DP: Low acceptance of Treatment in the Elderly for the Secondary Prevention of Osteoporotic Fracture in the Acute Rehabilitation Setting. Aging Clin Exp Res 2010, 22:231-237.

20. Wehren LE, Siris ES: Beyond bone mineral density: can existing clinical risk assessment instruments identify women at increased risk of osteoporosis? J Intern Med 2004, 256:375-380.

21. Ismail AA, Pye SR, Cockerill WC, Lunt M, Silman AJ, Reeve J, Banzer D, Benevolenskaya LI, Bhalla A, Bruges Armas J, Cannata JB, Cooper C, Delmas PD, Dequeker J, Dilsen G, Falch JA, Felsch B, Felsenberg D, Finn JD, Gennari C, Hoszowski K, Jajic I, Janott J, Johnell O, Kanis JA, Kragl G, Lopez Vaz A, Lorenc R, Lyritis G, Marchand F, Masaryk P, Matthis C, Miazgowski T, Naves-Diaz M, Pols HA, Poor G, Rapado A, Raspe HH, Reid DM, Reisinger W, Scheidt-Nave C, Stepan J, Todd C, Weber K, Woolf AD, O'Neill TW: Incidence of limb fracture across Europe: results from the European Prospective Osteoporosis Study (EPOS). Osteoporos Int 2002, 13:565-571.

22. Cadarette SM, Jaglal SB, Kreiger N, Mcisaac WJ, Darlington GA, Tu JV: Development and validation of the Osteoporosis Risk Assessment Instrument to facilitate selection of women for bone densitometry. CMA 2000, 162:1289-1294

23. Joakimsen RM, Fonnebo V, Magnus JH, Tollan A, Sogaard AJ: The Tromso Study: body height, body mass index and fractures. Osteoporos Int 1998 8:436-442.

24. Kanis JA, Borgstrom F, De Laet $C$, Johansson $H$, Johnell $O$, Jonsson $B$, Oden A, Zethraeus N, Pfleger B, Khaltaev N: Assessment of fracture risk. Osteoporos Int 2005, 16:581-589.

25. Bainbridge KE, Sowers M, Lin X, Harlow SD: Risk factors for low bone mineral density and the 6-year rate of bone loss among premenopausal and perimenopausal women. Osteoporos Int 2004, 15:439-446.

26. Krall EA, Dawson-Hughes B: Smoking increases bone loss and decreases intestinal calcium absorption. J Bone Miner Res 1999, 14:215-220.

27. Law MR, Hackshaw AK: A meta-analysis of cigarette smoking, bone mineral density and risk of hip fracture: recognition of a major effect. BMJ 1997, 315:841-846.
28. Vestergaard P, Rejnmark L, Mosekilde L: Fracture risk associated with use of antiepileptic drugs. Epilepsia 2004, 45:1330-1337.

29. Petty SJ, O'Brien TJ, Wark JD: Anti-epileptic medication and bone health. Osteoporos Int 2007, 18:129-142.

30. Schmitz B: Depression and mania in patients with epilepsy. Epilepsia 2005, 46-4:45-49

31. Cummings SR, Nevitt MC, Browner WS, Stone K, Fox KM, Ensrud KE, Cauley J, Black D, Vogt TM: Risk factors for hip fracture in white women. Study of Osteoporotic Fractures Research Group. N Engl J Med 1995, 332:767-773.

32. Van Der Klift M, De Laet CE, McCloskey EV, Johnell O, Kanis JA, Hofman A, Pols HA: Risk factors for incident vertebral fractures in men and women: the Rotterdam Study. J Bone Miner Res 2004, 19:1172-1180.

33. Belaya ZE, Melnichenko GA, Rozhinskaya LY, Fadeev W, Alekseeva TM Dorofeeva OK, Sasonova NI, Kolesnikova GS: Subclinical hyperthyroidism of variable etiology and its influence on bone in postmenopausal women. Hormones (Athens) 2007, 6:62-70.

34. Morris MS: The association between serum thyroid-stimulating hormone in its reference range and bone status in postmenopausal American women. Bone 2007, 40:1128-1134

35. Biondi B, Palmieri EA, Klain M, Schlumberger M, Filetti S, Lombardi G: Subclinical hyperthyroidism: clinical features and treatment options. Eur J Endocrinol 2005, 152:1-9.

36. Kanatani M, Sugimoto T, Sowa H, Kobayashi T, Kanzawa M, Chihara K: Thyroid hormone stimulates osteoclast differentiation by a mechanism independent of RANKL-RANK interaction. J Cell Physiol 2004, 201:17-25.

37. Garnero P, Vassy V, Bertholin A, Riou JP, Delmas PD: Markers of bone turnover in hyperthyroidism and the effects of treatment. $J$ Clin Endocrinol Metab 1994, 78:955-959.

38. Dargent-Molina P, Poitiers F, Breart G: In elderly women weight is the best predictor of a very low bone mineral density: evidence from the EPIDOS study. Osteoporos Int 2000, 11:881-888.

39. Bauman WA, Spungen AM, Wang J, Pierson RN, Schwartz E: Continuous loss of bone during chronic immobilization: a monozygotic twin study. Osteoporos Int 1999, 10:123-127.

40. Hearn AP, Silber E: Osteoporosis in multiple sclerosis. Mult Scler 2010 16:1031-1043.

41. Binkley N, Ramamurthy R, Krueger D: Low vitamin D status: definition, prevalence, consequences, and correction. Endocrinol Metab Clin North Am 2010, 39:287-301.

42. Sitges-Serra A, Garcia L, Prieto R, Pena MJ, Nogues X, Sancho J: Effect of parathyroidectomy for primary hyperparathyroidism on bone mineral density in postmenopausal women. Br J Surg 2010, 97:1013-1019.

43. Giusti A, Barone A, Pioli G, Girasole G, Razzano M, Pizzonia M, Pedrazzoni M, Palummeri E, Bianchi G: Heterogeneity in Serum 25-Hydroxy-Vitamin D Response to Cholecalciferol in Elderly Women with Secondary Hyperparathyroidism and Vitamin D Deficiency. J Am Geriatr Soc 2010, 58:1489-1495.

44. Diaz-Martin MA, Traba ML, De La Piedra C, Guerrero R, Mendez-Davila C, De La Pena EG: Aminoterminal propeptide of type I collagen and bone alkaline phosphatase in the study of bone metastases associated with prostatic carcinoma. Scand J Clin Lab Invest 1999, 59:125-132.

45. Garnero P, Vergnaud P, Hoyle N: Evaluation of a fully automated serum assay for total $\mathrm{N}$-terminal propeptide of type I collagen in postmenopausal osteoporosis. Clin Chem 2008, 54:188-196.

46. Nishizawa Y, Nakamura T, Ohta H, Kushida K, Gorai I, Shiraki M, Fukunaga M, Hosoi T, Miki T, Chaki O, Ichimura S, Nakatsuka K, Miura M: Guidelines for the use of biochemical markers of bone turnover in osteoporosis (2004). J Bone Miner Metab 2005, 23:97-104

47. Raisz LG: Clinical practice. Screening for osteoporosis. N Engl J Med 2005, 353:164-171.

48. Seibel MJ: Clinical use of markers of bone turnover in metastatic bone disease. Nat Clin Pract Oncol 2005, 2:504-517.

49. Leboff MS, Narweker R, Lacroix A, Wu L, Jackson R, Lee J, Bauer DC, Cauley J, Kooperberg C, Lewis C, Thomas AM, Cummings S: Homocysteine levels and risk of hip fracture in postmenopausal women. J Clin Endocrinol Metab 2009, 94:1207-1213.

50. Yilmaz N, Eren E: Homocysteine oxidative stress and relation to bone mineral density in post-menopausal osteoporosis. Aging Clin Exp Res 2009, 21:353-357. 
51. Krivosikova Z, Krajcovicova-Kudlackova M, Spustova V, Stefikova K, Valachovicova M, Blazicek P, Nemcova T: The association between high plasma homocysteine levels and lower bone mineral density in Slovak women: the impact of vegetarian diet. Eur J Nutr 2010, 49:147-153.

52. Herrmann M, Joseph J, Tyagi SC: Homocysteine, brain natriuretic peptide and chronic heart failure: a critical review. Clin Chem Lab Med 2007, 45:1633-1644.

Pre-publication history

The pre-publication history for this paper can be accessed here: http://www.biomedcentral.com/1471-2474/12/187/prepub

doi:10.1186/1471-2474-12-187

Cite this article as: Kolios et al.: Anamnestic risk factor questionnaire as reliable diagnostic instrument for osteoporosis (reduced bone morphogenic density). BMC Musculoskeletal Disorders 2011 12:187.

\section{Submit your next manuscript to BioMed Central} and take full advantage of:

- Convenient online submission

- Thorough peer review

- No space constraints or color figure charges

- Immediate publication on acceptance

- Inclusion in PubMed, CAS, Scopus and Google Scholar

- Research which is freely available for redistribution

Submit your manuscript at www.biomedcentral.com/submit 